\title{
黒鉛炉原子吸光法を用いるインジウム及びガリウムの 定量における硫酸塩干渉の抑制
}

\author{
松㟝 浩司 ${ }^{\circledR}$, 佐田 俊勝*
}

(1994 年 3 月 17 日受理)

\section{1 緒言}

黒鉛炉 AAS を用いて In や Ga を定量する場合, そ れらの酸化物が揮発性のため原子化以前での揮散が大き く，見掛けの感度は低い，この揮散を抑制するために， マトリックス修飾剤として $\mathrm{Ni}$ と $\mathrm{Al}$ の混合硝酸塩の添 加を提唱した ${ }^{1) 2}$. 更に EDTA アンモニウム塩を同時に 添加することにより共存塩化物の干渉も抑制可能となっ た. 黒鉛炉 AAS 法における In の干渉の報告は少なく ${ }^{3)}$, むしろ塩化物干渉の抑制に硫 酸塩が添加されている( ${ }^{4) 5}$. しかし，アルカリ金属硫酸 塩の干渉は大きく，提唱した修飾剤では干渉抑制は不完 全である、このため, 硫酸塩干渉を更に抑制するために この修飾剤の改善を試みた。

\section{2 実験}

\section{$2 \cdot 1$ 装置及び試薬}

原子吸光分析装置: 日立製 180-30 型に同社製 GA2B 型原子化装置, オートサンプラー及び記録計として D-2500 型クロマトインテグレーターを取り付けて使用 した．黒鉛炉としてはチューブ型のものを，雾囲気ガス としてはアルゴンを用いた。浜松ホトニクス製 In 及び $\mathrm{Ga}$ 中空陰極ランプを光源とし, 重水素ランプによるバ ックグラウンド補正を行った.

試楽は既報122) と同様に処理した。

\section{$2 \cdot 2$ 実耠操作}

$10 \mu \mathrm{l}$ の試料をオートサンプラーで黒鉛炉に注入し, アルゴン雾囲気下で乾燥, 灰化, 原子化を順に行った. アルゴン流量としては, シースガスとして $2.01 \mathrm{~min}^{-1}$,

* 山口大学工学部応用化学工学科: 755 山口県宇部市常 盤台
キャリヤーガスとして $0.11 \mathrm{~min}^{-1}$ とした. 乾燥 $\left(90^{\circ} \mathrm{C}\right.$, 30 秒) と原子化 $\left(2800^{\circ} \mathrm{C}, 5\right.$ 秒 $)$ の条件は一定とした. 灰化条件は, 特に断らないかぎり $750^{\circ} \mathrm{C}, 30$ 秒とした。 原子化過程での $303.9 \mathrm{~nm}$ (バンドパス $1.3 \mathrm{~nm}$ ) におけ る In 及び $287.4 \mathrm{~nm}$ (バンドパス $1.3 \mathrm{~nm}$ ) における $\mathrm{Ga}$ の吸光度を記録させ，ピーク高さで読み取った．硫酸塩 の干渉は, その塩の存在下における In 及び $\mathrm{Ga}$ の吸光 度を同じ条件下でのその塩が存在しないときの値を基準 とした相対吸光度で示した。

\section{3 結果と考察}

\section{3・1 インジウムに対する硫酸塩の干渉及び抑制}

In の定量に対しては, $0.004 \mathrm{M} の ~ \mathrm{Ni}\left(\mathrm{NO}_{3}\right)_{2}$ と 0.001 $\mathrm{M}$ の $\mathrm{Al}\left(\mathrm{NO}_{3}\right)_{3}$ の組み合わせがマトリックス修飾剤と して最適であった 1 .これらの存在下で硫酸塩の干渉を 調べるために, 硫酸塩の添加濃度を $10^{-4}$ から $10^{-1} \mathrm{M}$ へ変化させ, In の相対吸光度を測定した. Fig. 1 の （A）に示されるように, 硝酸酸性の場合は $\mathrm{Na}_{2} \mathrm{SO}_{4}$ は $10^{-4} \mathrm{M}$ 以上で大きな干渉を示している. 硝酸の代わり に $\operatorname{EDTA}\left(\mathrm{NH}_{4}\right)_{4}$ を添加すれば, $\mathrm{Na}_{2} \mathrm{SO}_{4}$ の許容共存量 は約 10 倍増加している. $\mathrm{K}_{2} \mathrm{SO}_{4}$ についても同様な結果 が得られた.これに比べ $\mathrm{Ni}, \mathrm{Al}$ や $\mathrm{Cu}$ の硫酸塩の干渉 は小さかった。 $\mathrm{Ni}, \mathrm{Al}$ 及び $\mathrm{Cu}$ 塩の分解温度はそれぞれ 848,770 及び $650^{\circ} \mathrm{C}$ である ${ }^{6)}$. 又, $\mathrm{Na}$ と $\mathrm{K}$ の硫酸塩の 融点は 884 及び $1069^{\circ} \mathrm{C}$ であり ${ }^{6)}$, 分解は更に高温で生 じるであろう。このように Na と $\mathrm{K}$ 塩の分解温度は他 の塩に比べて高く, それらの灰化過程での分解除去は困 難であり, 高温で熱分解する際に揮発性の In 硫化物が 生成し干渉が生じるのであろう. Zhou ら ${ }^{7)}$ は, 黒鉛炬 中で In の硫化物を生成させ, その分子吸収の測定によ り硫黄を定量している. $\operatorname{EDTA}\left(\mathrm{NH}_{4}\right)_{4}$ の干渉抑制効果 は, EDTA の In や共存金属へのマスキング効果, 更に 


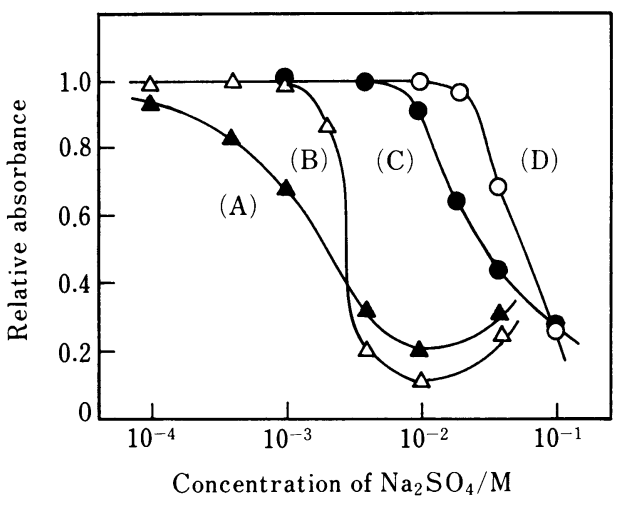

Fig. 1 Removal of sodium sulfate interference with indium by addition of matrix modifier

All the test solutions contain $0.20 \mu \mathrm{g} \mathrm{ml}^{-1}$ In and $0.001 \mathrm{M} \mathrm{Al}\left(\mathrm{NO}_{3}\right)_{3}$. (A) $0.004 \mathrm{M} \mathrm{Ni}\left(\mathrm{NO}_{3}\right)_{2}+0.1 \mathrm{M}$ $\mathrm{HNO}_{3}$; (B) $0.004 \mathrm{M} \mathrm{Ni}\left(\mathrm{NO}_{3}\right)_{2}+0.02 \mathrm{M}$ EDTA$\left(\mathrm{NH}_{4}\right)_{4}$; (C) $0.1 \mathrm{M} \mathrm{Ni}\left(\mathrm{NO}_{3}\right)_{2}+0.1 \mathrm{M} \mathrm{HNO}_{3}$; (D) 0.1 $\mathrm{M} \mathrm{Ni}\left(\mathrm{NO}_{3}\right)_{2}+0.1 \mathrm{M} \operatorname{EDTA}\left(\mathrm{NH}_{4}\right)_{4}$

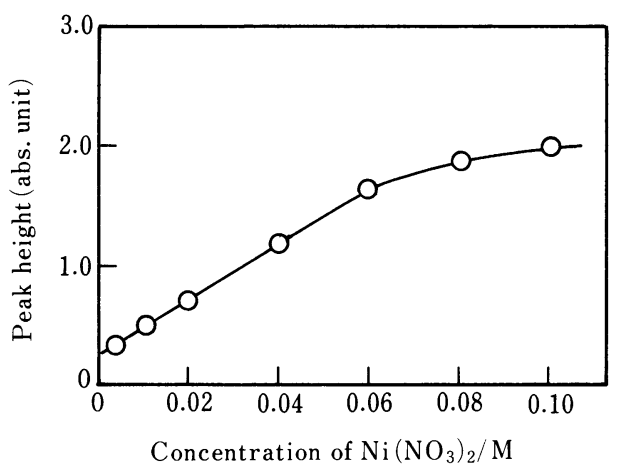

Fig. 2 Effect of nickel nitrate concentration on the atomic absorbance of indium in the presence of sodium sulfate

All test solutions contain $0.20 \mu \mathrm{g} \mathrm{ml}^{-1}$ In, $0.02 \mathrm{M}$ $\mathrm{Na}_{2} \mathrm{SO}_{4}, 0.001 \mathrm{M} \mathrm{Al}\left(\mathrm{NO}_{3}\right)_{3}$ and $0.1 \mathrm{M} \mathrm{HNO}_{3}$

乾燥過程で生じるであろう $\left(\mathrm{NH}_{4}\right)_{2} \mathrm{SO}_{4}$ の灰化過程での 分解除去により, In の硫化物生成が抑制されるためで あろう。

硫酸塩に対する，干渉抑制効果を改善させるために， $\mathrm{Al}\left(\mathrm{NO}_{3}\right)_{3}$ の濃度は一定とし, $\mathrm{Ni}\left(\mathrm{NO}_{3}\right)_{2}$ の添加濃度を 変化させ, $\mathrm{Na}_{2} \mathrm{SO}_{4}$ 共存下での $\mathrm{In}$ の吸光度への影響を 調べた. Fig. 2 に示されるように, Ni 塩濃度が高いほ よ゙ In の吸光度は増加し, 干渉抑制効果は大きくなる. しかし，その濃度が高い場合は, In の吸収信号の再現
性が悪くなり，0.1 M が添加量としては限界であった。 $\mathrm{Al}\left(\mathrm{NO}_{3}\right)_{3}$ についても $\mathrm{Ni}\left(\mathrm{NO}_{3}\right)_{2}$ 濃度を一定にしてその 添加濃度の影響を調べた。しかし，0.001 M 以上ではそ の効果にはほとんど変化は認められず，添加濃度は $0.001 \mathrm{M}$ のままとした。

$\mathrm{Ni}\left(\mathrm{NO}_{3}\right)_{2}$ を $0.04 \mathrm{M}, \mathrm{Al}\left(\mathrm{NO}_{3}\right)_{3}$ を $0.001 \mathrm{M}$ 添加した 場合の In の吸光度への灰化温度の影響を調べた。硝酸 酸性で硫酸塩が存在しないときは最大許容灰化温度は約 $1000^{\circ} \mathrm{C}$ であった. $\mathrm{Na}_{2} \mathrm{SO}_{4}$ を添加すると In の吸光度は 低下するが，その最大許容灰化温度は変化しなかった。 $\operatorname{EDTA}\left(\mathrm{NH}_{4}\right)_{4}$ を添加した場合, その最大許容灰化温度 は約 $900^{\circ} \mathrm{C}$ に低下し, $\mathrm{Na}_{2} \mathrm{SO}_{4}$ が共存すると更に約 $800^{\circ} \mathrm{C}$ に低下した. $\mathrm{K}_{2} \mathrm{SO}_{4}$ 共存の場合にも同様な現象 が認められた。このように EDTA は硫酸塩の干渉抑制 に有効であるが，許容灰化温度を低下させるような干渉 を示した．それは硫酸塩によって更に強められた。この ような EDTA 及び硫酸塩の灰化温度への影響は $\mathrm{Tl}^{8)}$ を 定量する際にも認められている。この結果から，In の 吸光度を測定する際の灰化温度は $750^{\circ} \mathrm{C}$ とした。

$\mathrm{Ni}\left(\mathrm{NO}_{3}\right)_{2}$ を $0.1 \mathrm{M}$ 添加した場合の $\mathrm{Na}_{2} \mathrm{SO}_{4}$ の干渉 を Fig. 1 の (C) と（D）に示す.硝酸酸性の場合より も $\operatorname{EDTA}\left(\mathrm{NH}_{4}\right)_{4}$ を $\mathrm{Ni}$ と当量添加した場合のほうが干 渉抑制効果はよく, $\mathrm{Ni}\left(\mathrm{NO}_{3}\right)_{2}$ を $0.004 \mathrm{M}$ 添加した場合 に比べ, $\mathrm{Na}_{2} \mathrm{SO}_{4}$ の許容共存量は硝酸酸性では約 100 倍, EDTA 添加では約 20 倍増加している. $\mathrm{K}_{2} \mathrm{SO}_{4}$ の 干渉についても同様な結果が得られた。 $\mathrm{Cu}, \mathrm{Zn}, \mathrm{Ni}, \mathrm{Al}$ 及び Co の硫酸塩ではそれらが $0.1 \mathrm{M}$ 以下では干渉は 認められなかった。

\section{3 •2 ガリウムに対する硫酸塩の干渉及び抑制}

Ga に対する硫酸塩の干渉は, In の場合に似ている.

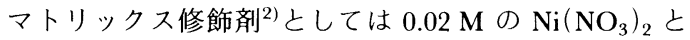
$0.001 \mathrm{M}$ の $\mathrm{Al}\left(\mathrm{NO}_{3}\right)_{3}$ の組み合わせが提唱された. In の場合に比べて $\mathrm{Ni}\left(\mathrm{NO}_{3}\right)_{2}$ の濃度が高いため, Fig. 3 の（A）と（B）に示されるように, $\mathrm{Na}_{2} \mathrm{SO}_{4}$ の $\mathrm{Ga}$ 原 子吸収への干渉は In に対するよりは小さい。この場合 も $\operatorname{EDTA}\left(\mathrm{NH}_{4}\right)_{4}$ を添加するほうが抑制効果は良好であ る. $\mathrm{K}_{2} \mathrm{SO}_{4}$ に対しても同様な効果が認められた。これ に比べて In の場合と同様に, Cu, Zn, Ni 及び Co の硫 酸塩の干渉は $0.1 \mathrm{M}$ 以下では認められなかった。

干渉抑制効果を改善するために，In の場合と同様 に, $\mathrm{Ni}\left(\mathrm{NO}_{3}\right)_{2}$ 及び $\mathrm{Al}\left(\mathrm{NO}_{3}\right)_{3}$ の添加濃度の影響を調べ た、Ni 塩は添加量が大きいほど抑制効果は良好であっ た. $\mathrm{Al}$ 塩の効果は $0.001 \mathrm{M}$ 以上ではほとんど変わらな かった，灰化温度の影響も同様に調べた。最大許容灰化 


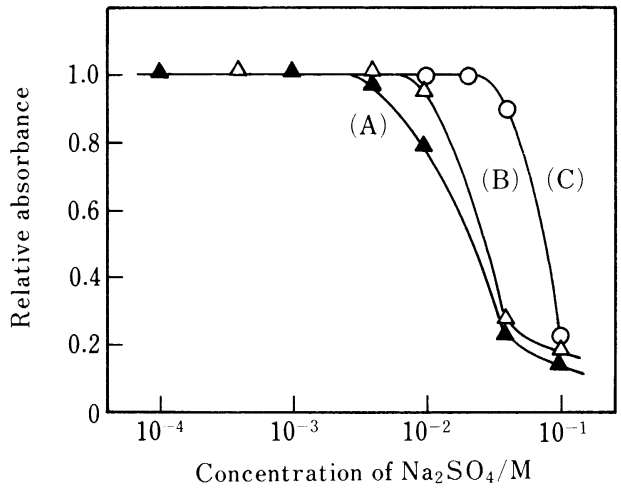

Fig. 3 Removal of sodium sulfate interference with gallium by addition of matrix modifier

All test solutions contain $0.20 \mu \mathrm{g} \mathrm{ml}^{-1} \mathrm{Ga}$ and 0.004 $\mathrm{M} \mathrm{Al}\left(\mathrm{NO}_{3}\right)_{3}$. (A) $0.02 \mathrm{M} \mathrm{Ni}\left(\mathrm{NO}_{3}\right)_{2}+0.1 \mathrm{M} \mathrm{HNO}_{3}$; (B) $0.02 \mathrm{M} \mathrm{Ni}\left(\mathrm{NO}_{3}\right)_{2}+0.05 \mathrm{M} \operatorname{EDTA}\left(\mathrm{NH}_{4}\right)_{4} ;$ (C) $0.1 \mathrm{M} \mathrm{Ni}\left(\mathrm{NO}_{3}\right)_{2}+0.1 \mathrm{M} \operatorname{EDTA}\left(\mathrm{NH}_{4}\right)_{4}$

温度は硝酸酸性の場合は約 $1200^{\circ} \mathrm{C}$ であったが, EDTA を添加すれば約 $1000^{\circ} \mathrm{C}$ に低下し，これに硫酸塩を共存 させると更に約 $900^{\circ} \mathrm{C}$ に低下した。よって， $\mathrm{Ga}$ 吸光度 を測定する場合も灰化温度は $750^{\circ} \mathrm{C}$ とした. $\mathrm{Ni}\left(\mathrm{NO}_{3}\right)_{2}$ を $0.1 \mathrm{M}, \mathrm{Al}\left(\mathrm{NO}_{3}\right)_{3}$ を $0.001 \mathrm{M}$, 及び $\operatorname{EDTA}\left(\mathrm{NH}_{4}\right)_{4}$ を $0.1 \mathrm{M}$ 添加した場合の $\mathrm{Na}_{2} \mathrm{SO}_{4}$ の干渉を Fig. 3 の (C)
に示す。 $0.02 \mathrm{M}$ 以下であれば干渉は完全に抑制されて いる. $\mathrm{K}_{2} \mathrm{SO}_{4}$ の場合も同様な結果が得られた。

黒鉛炉 AAS で In と Ga を定量する場合，アルカリ 金属硫酸塩の干渉は大きい。これを抑制するためには, マトリックス修飾剤として添加する $\mathrm{Ni}$ と $\mathrm{Al}$ の混合硝 酸塩の $\mathrm{Ni}$ 塩濃度を高くすればよい. $\operatorname{EDTA}\left(\mathrm{NH}_{4}\right)_{4}$ を 添加すれば，抑制効果は更に良好であり，この場合硫酸 塩と共に塩化物が共存してもそれらの干渉は同時に抑制 可能である.

\section{文献}

1) 松㟝浩司: 分析化学, 39, 823 (1990).

2) K. Matsusaki, M. Izuchi: Anal. Sci., 7, 159 (1991).

3) 斉加実彦, 矢崎弘明, 藤沼 弘: 分析化学, 34, T109 (1985).

4) B. Ya. Spivakov, L. N. Sukhoveeva, K. Dittrich, A. V. Karyakin, Yu. A. Zolotov: Zh. Anal. Khim., 34, 1947 (1979).

5) X.-Q. Shan, Z.-N. Yuan, Z.-M. Ni: Anal. Chem., 57, 857 (1985).

6) 日本化学会編: “化学便覧基礎編 I (改定 4 版)”, pp. 118２31（1993）,(丸善).

7) X.-L. Zhou, J.-C. Shao, M.-H. Zhu: Guangpuxue Yu Guangpu Fenxi, 13, 121 (1993): Anal. Abstr., 55, 12 H125 (1993).

8) K. Matsusaki, T. Oishi: Anal. Sci., 9, 381 (1993).

Removal of sulfate interference in the determination of indium and gallium by graphite furnace AAS. Koji MATSUSAKI and Toshikatsu SATA (Department of Applied Chemistry and Chemical Engineering, Faculty of Engineering, Yamaguchi University, Tokiwadai, Ube-shi, Yamaguchi 755)

A mixture of ammonium-EDTA, nickel and aluminium nitrates is suitable as a matrix modifier for the removal of sulfate interference in the determination of indium and gallium by graphite furnace AAS. Nickel and aluminium nitrates act as a thermal stabilizer for the analyte in the furnace before atomization. Since analyte and other cations are masked by EDTA, the coexisting sulfates are converted to ammonium salt, which is readily decomposed and eliminated from the furnace during the ashing step. In the presence of $0.1 \mathrm{M}$ nickel nitrate, $0.001 \mathrm{M}$ aluminium nitrate and $0.1 \mathrm{M}$ ammonium-EDTA, when the concentration of sodium and potassium sulfates are below $0.02 \mathrm{M}$, the interferences of these sulfates are completely removed.

(Received March 17, 1994)

\section{Keyword phrases}

determination of indium; determination of gallium; AAS with a graphite furnace; matrix modifier; sulfate interference. 